\title{
The effect of bovine milk lactoferrin on human breast cancer cell lines
}

\author{
D. C. Duarte, A. Nicolau, J. A. Teixeira, and L. R. Rodrigues ${ }^{1}$ \\ Institute for Biotechnology and Bioengineering (IBB), Centre of Biological Engineering, Campus de Gualtar, 4710-057 Braga, Portugal
}

\begin{abstract}
The evidence that biologically active food components are key environmental factors affecting the incidence of many chronic diseases is overwhelming. However, the full extent of such components in our diet is unknown, as is our understanding of their mechanisms of action. Beyond the interaction of these food components with the gut and intestinal immune functions, whey proteins such as lactoferrin are being tested as anticancer agents. Lactoferrin is an iron-binding protein that has been reported to inhibit several types of cancer. In the present work, the effects of bovine milk lactoferrin on human breast cancer HS578T and T47D cells were studied. The cells were either untreated or treated with lactoferrin concentrations ranging from 0.125 to 125 $\mu M$. Lactoferrin decreased the cell viability of HS578T and T47D by 47 and 54\%, respectively, and increased apoptosis about 2-fold for both cell lines. Proliferation rates decreased by 40.3 and $63.9 \%$ for HS578T and T47D, respectively. For the T47D line, cell migration decreased in the presence of the protein. Although the mechanisms of action are not fully known, the results gathered in this work suggest that lactoferrin interferes with some of the most important steps involved in cancer development.
\end{abstract}

Key words: lactoferrin, breast cancer, viability and proliferation, apoptosis and migration

\section{INTRODUCTION}

Milk and dairy products have become recognized as functional foods, suggesting that their use has a direct and measurable effect on health outcomes; that is, that their consumption has been related to a reduced risk of numerous cancers (Marshall, 2004). Cancer is the second leading cause of mortality worldwide, with an expected 1.4 million persons being diagnosed with breast cancer in 2010. Hence, this is an enormously important health risk, and progress leading to enhanced

Received July 16, 2010.

Accepted September 19, 2010.

${ }^{1}$ Corresponding author: lrmr@deb.uminho.pt survival is a global priority (Schiff and Osborne, 2005; Jemal et al., 2009).

Breast cancer, like all other cancer types, is a result of 6 essential alterations in normal cells that represent good targets for treatment: the so-called cancer hallmarks (Hanahan and Weinberg, 2000). These include the ability to be self-sufficient in growth signals (tumor cells have reduced dependence on exogenous growth stimulation); to evade antigrowth signs and apoptosis; to achieve endless replicative potential; to sustain angiogenesis; to evade tissues; and to form metastases. Several strategies have been pursued in the last years to hamper the development of tumors or to treat existing ones (Hanahan and Weinberg, 2000).

An increasing interest has been reported on the use of biologically active substances from food (Gill et al., 2000; Perdigon et al., 2002; Tsuda et al., 2004; Ferguson, 2009; Jacobs et al., 2009; McCabe-Sellers et al., 2009). However, the full set of active components in our diet is unknown and knowledge on their mechanisms of action is scarce. Proteins and peptides existing in milk have been reported to be cancer-preventive agents (Tsuda et al., 2000; Korhonen and Pihlanto, 2006; Wakabayashi et al., 2006; Rodrigues et al., 2009) such as lactoferrin $(\mathbf{L F})$, which is also known for its inhibitory action on cell proliferation, as well as for its antiinflammatory and antioxidant abilities (Tomita et al., 2002; Tsuda et al., 2002, 2010; Legrand et al., 2005; Ward et al., 2005; Pan et al., 2007; Iigo et al., 2009; Rodrigues et al., 2009).

Lactoferrin is an iron-binding glycoprotein from the transferrin family that can be found in many different tissues or secretions, such as tears, saliva, blood, secondary granules of neutrophils, and milk (Tsuda et al., 2002; Pan et al., 2007; Rodrigues et al., 2009). In vivo studies show that oral administration of bovine LF to rodents significantly reduces chemically induced tumorigenesis in different organs (breast, esophagus, tongue, lung, liver, colon, and bladder) and inhibits angiogenesis (Tsuda et al., 2002; Iigo et al., 2009). It has been demonstrated that more than $60 \%$ of administered bovine LF survives passage through the adult human stomach and enters the small intestine in an intact form (Troost et al., 2001). Intact and partly intact bovine LF are likely to exert various physiological 
effects in the digestive tract. Moreover, subcutaneous administration of LF inhibits the growth of implanted solid tumors and exerts preventive effects on metastasis (Bezault et al., 1994).

These activities of LF have been attributed to its immunomodulatory potential and ability to activate T cells and natural killer cells (Bezault et al., 1994; Damiens et al., 1999). Lactoferrin is able to limit the growth of tumor cells, and it was shown that addition of exogenous LF to MDA-MB-231 breast cancer cell lines culture media induced cell cycle arrest at the $\mathrm{G}_{1} / \mathrm{S}$ transition (Damiens et al., 1999). In addition, LF was found to induce growth arrest and nuclear accumulation of Smad-2 in HeLa cells (Zemann et al., 2010). According to Babina and coworkers (2005), LF possesses DNase activity and is cytotoxic, suppressing the growth of several human and mouse cell lines. Recent studies demonstrated that LF has an estrogen element of response (ERE; Teng, 2006) that confers the protein the ability to interfere with the genetic expression of several molecules that are vital for cell survival. Furthermore, LF was found to induce apoptosis in several human cell lines, as for example A459 lung cells, Caco-2 intestine cells, and HTB9 kidney cells (Hakansson et al., 1995), and to inhibit Akt activation and modulate its downstream protein phosphorylation in apoptosis of SGC-7901 human stomach cancer cells (Xu et al., 2010). Moreover, LF is effective against melanoma cells (Pan et al., 2007), decreasing the proliferation rates and increasing apoptosis levels. Xiao and coworkers (2004) also reported inhibitory effects of LF on head and neck cancer cells, downregulating $\mathrm{G}_{1}$ cyclin-dependent kinases, and therefore influencing the cell cycle. Finally, LF has been reported to suppress cell-induced angiogenesis in mice and to increase the IL-18 production (Xiao et al., 2004).

Knowledge on the effect of diet components on health will create opportunities for cancer prevention through profound alterations in diet regimens. Over time, small but recurrent doses of bioactive proteins may prevent the carcinogenic process by decreasing the rate of cell proliferation and the growth of cancer cells. In the current work, the effect of a range of LF concentrations at different exposure times on cell viability, proliferation, apoptosis, and migration using 2 model human breast cancer cell lines, HS578S and T47D, was studied. We used 2 cell lines because of their differences in the estrogen receptor. Cells lacking the estrogen receptor (e.g., HS578T) usually correspond to a more aggressive type of tumor for which the existent therapy is not very efficient. Therefore, if LF shows an effect for these type of cells, it would represent an important scientific advance. On the other hand, for cells that possess the estrogen receptor (e.g., T47D), if an effect is proved for
LF, then a combination with estrogen could be further explored for breast cancer therapeutics.

\section{MATERIALS AND METHODS}

\section{Lactoferrin}

Lactoferrin (Sigma-Aldrich Co., St. Louis, MO) was dissolved in PBS $(1 \mathrm{~g} / \mathrm{L} \mathrm{NaCl}, 0.2 \mathrm{~g} / \mathrm{L} \mathrm{KCl}, 0.24$ $\mathrm{g} / \mathrm{L} \mathrm{Na}_{2} \mathrm{HPO}_{4} \cdot 2 \mathrm{H}_{2} \mathrm{O}, 1.805 \mathrm{~g} / \mathrm{L} \mathrm{KH}_{2} \mathrm{PO}_{4}, \mathrm{pH}$ 7.4) to obtain different protein solution concentrations $(0.125$, $6.25,12.5$, and $125 \mu M)$. All LF solutions were passed through a $0.2-\mu \mathrm{m}$ filter before use and stored at $4^{\circ} \mathrm{C}$.

\section{Breast Cancer Cell Lines}

Breast cancer cell lines HS578T and T47D, were kindly provided by the Institute of Molecular Pathology and Immunology of the University of Porto (IPATIMUP, Porto, Portugal). The HS578T cell strain was derived from a carcinoma of the breast and is negative for estrogen receptor $(\mathbf{E R}-)$. The T47D line was isolated from a pleural effusion obtained from a 54-yr-old female patient with an infiltrating ductal carcinoma of the breast and is positive for estrogen receptor $(\mathbf{E R}+)$. The cells were maintained in an incubator with a $5 \%$ $\mathrm{CO}_{2}$ atmosphere at $37^{\circ} \mathrm{C}$. The culture medium used was the Dulbecco's modified Eagle medium (DMEM; GIBCO, Invitrogen, Barcelona, Spain) supplemented with 10\% fetal bovine serum (GIBCO, Invitrogen) and 1\% penicillin/streptomycin (Invitrogen).

\section{Cell Viability}

Two distinct methods were used to evaluate the cell viability to LF exposure, as described below.

\section{Trypan Blue Method}

Cells were grown in 6-well plates until a concentration of $1 \times 10^{5}$ cells per well was achieved. Adequate volumes of the previously prepared LF solutions were added to each well to obtain the required LF concentrations $(0.125,6.25,12.5$, and $125 \mu M)$. Additionally, control wells were included consisting of DMEM medium and PBS (no LF added). The plates were incubated for 24, 48 , and $72 \mathrm{~h}$. Subsequently, the supernatant of each well was collected into a Falcon tube. The adhered cells were washed with PBS, trypsinized, and then collected into the respective Falcon tube. All tubes were centrifuged $(700 \times g, 5 \mathrm{~min})$ and the supernatant was discarded. The remaining pellet was resuspended in $100 \mu \mathrm{L}$ of PBS. The collected cell volumes were diluted 1:1 with trypan blue (TB; Sigma-Aldrich Co.), and the viable 
and nonviable cells were counted in a Neubauer chamber by using an inverted optical microscope equipped with a $20 \times$ objective. The results were expressed as percentage of viable cells compared with the control and represent an average of 3 independent cultures with 8 wells per concentration in each experiment.

\section{MTS Method}

The cell viability to LF exposure was also determined using the MTS [3-(4,5-dimethylthiazol-2-yl)-5-(3carboxymethoxyphenyl)-2-(4-sulfophenyl)-2H-tetrazo-

lium] method. A commercial kit was used according to the manufacturer instructions (PROM G35800001, Promega, Lisbon, Portugal). In these experiments, $100 \mu \mathrm{L}$ of cell suspension was added to each well of a 96-well plate. Additionally, control wells were included that consisted of DMEM medium and PBS. When a cell concentration of $1 \times 10^{5}$ cells $/ \mathrm{mL}$ was obtained, adequate volumes of LF solutions were added to the wells and incubated for different exposure times $(24,48$, and $72 \mathrm{~h}$ ). Then, $20 \mu \mathrm{L}$ of the CellTiter 96 AQueous One solution cell proliferation assay reagent (MTS, Promega G35800001 kit) was added to each well and the plates incubated $\left(37^{\circ} \mathrm{C}, 5 \% \mathrm{CO}_{2}\right)$ for $3 \mathrm{~h}$, after which the cell viability was quantified by recording the absorbance at $490 \mathrm{~nm}$. The results were expressed as percentage of viable cells compared with the control and represent an average of 3 independent cultures with 8 wells per concentration in each experiment.

\section{Apoptosis}

The effect of different LF concentrations $(0.125,6.25$, 12.5 , and $125 \mu M)$ and exposure times $(24,48$, and 72 h) in cell apoptosis was assessed using a commercial kit (PROM G 8091, Promega) with the same experimental setup as described above. After exposing the cells, at a concentration of $1 \times 10^{4}$ cells $/ \mathrm{mL}$, to $\mathrm{LF}\left(37^{\circ} \mathrm{C}, 5 \%\right.$ $\mathrm{CO}_{2}$ ), $100 \mu \mathrm{L}$ of Caspase-Glo $3 / 7$ reagent (PROM G 8091, Promega) was added to the wells, and the plates were left to stand for $3 \mathrm{~h}$ at room temperature and in the dark. Then, apoptosis levels were determined by luminescence recording. The average blank value (DMEM medium alone) was 2,845 relative luminescence units, and that for the experiments conducted with T47D and HS578T was 642 relative luminescence units. The blank value was subtracted from all the other values. The luminescence of the cells in medium (control) lay above this value and is given by $0 \mu M \mathrm{LF}$. The results represent an average of 3 independent cultures with 8 wells per concentration in each experiment.

\section{Cell Proliferation}

Cell proliferation was determined using the bromodeoxyuridine (5-bromo-2-deoxyuridine, BrdU; SigmaAldrich Co.) assay. Briefly, a lamella was placed in each well of a 24-well plate and cells were grown until a cell concentration of $1 \times 10^{5}$ cells per well was reached. These experiments were conducted using only $12.5 \mu \mathrm{M}$ LF. After $48 \mathrm{~h}$ of exposure to LF, $50 \mu \mathrm{L}$ of BrdU per $\mathrm{mL}$ of culture medium was added to each well and the plates were incubated $\left(37^{\circ} \mathrm{C}, 5 \% \mathrm{CO}_{2}\right)$ for $3 \mathrm{~h}$. Afterward, the cells were washed with PBS and left at $4^{\circ} \mathrm{C}$ in $1 \mathrm{~mL}$ of paraformaldehyde $1 \%$ (wt/vol, prepared in PBS). Subsequently, the fixed cells were treated with $2 \mathrm{M} \mathrm{HCl}$ at room temperature for $30 \mathrm{~min}$. Next, the lamellas were washed with PBS-0.5\% Tween $20-0.05 \%$ BSA and incubated with anti-BrdU (mouse) (Dako Denmark, Glostrup, Denmark) at a 1:1 dilution with PBS- $0.5 \%$ Tween 20-0.05\% BSA. After $1 \mathrm{~h}$, lamellas were washed twice with PBS-0.5\% Tween $20-0.05 \%$ BSA, and subsequently incubated with anti-mouse Ig fluorescein isothiocyanate (FITC; Dako Denmark) at a 1:100 dilution in PBS- $0.5 \%$ Tween $20-0.05 \%$ BSA for 30 min. Finally, the lamellas were washed with PBS- $0.5 \%$ Tween $20-0.05 \%$ BSA. The nuclei were counted by using a fluorescence microscope (Zeiss HBO-50, Carl Zeiss, Jena, Germany) using a $40 \times$ magnification. The total nuclei were stained with 4',6-diamidino-2-phenylindole (blue) and the nuclei in proliferation were stained with FITC (green). Proliferation rates were determined as the percentage ratio between the number of nuclei in proliferation and total number of nuclei. The results represent an average of 3 independent cultures and 10 measures for each culture.

\section{Migration}

A suspension containing $1 \times 10^{5}$ cells was left to grow in 6 -well plates until $90 \%$ confluence was achieved. Next, adhered cells were washed twice with PBS. Then, a wound was inflicted in the center of each well by using a needle, and 3 spots were marked on the wound as reference points. Then, fresh DMEM medium was added to the wells, and an adequate volume of LF solution was added to obtain a concentration of $12.5 \mu \mathrm{M}$. During the $48 \mathrm{~h}$ of exposure, pictures were taken at the predefined measuring spots using an inverted microscope (Nikon Diaphot 300, Nikon, Portugal) equipped with a $20 \times$ objective. The images were captured by a video camera (Sony CCD, Sony, Portugal) and processed using the Image Pro-Plus software (version 7.0, Media Cybernetics, Bethesda, MD), which allowed the measurement of 
Table 1. Effect of lactoferrin treatment $(0.125,6.25,12.5$, and $125 \mu M)$ on HS578T and T47D breast cancer cells for different exposure times $(24,48$, and $72 \mathrm{~h})$, by 2 complementary tests: trypan blue dye method and bioreduction of MTS [3-(4,5-dimethylthiazol-2-yl)-5-(3carboxymethoxyphenyl)-2-(4-sulfophenyl)-2H-tetrazolium] $]^{1}$

\begin{tabular}{|c|c|c|c|c|c|c|}
\hline \multirow[b]{2}{*}{ Lactoferrin $(\mu M)$} & \multicolumn{3}{|c|}{ HS578T } & \multicolumn{3}{|c|}{$\mathrm{T} 47 \mathrm{D}$} \\
\hline & $24 \mathrm{~h}$ & $48 \mathrm{~h}$ & $72 \mathrm{~h}$ & $24 \mathrm{~h}$ & $48 \mathrm{~h}$ & $72 \mathrm{~h}$ \\
\hline 0.125 & $92.9 \pm 6.0^{*}$ & $91.6 \pm 3.9^{* *}$ & $41.6 \pm 8.6^{* *}$ & $95.6 \pm 5.2^{*}$ & $93.4 \pm 5.2$ & $97.9 \pm 5.7$ \\
\hline 6.25 & $75.4 \pm 7.3^{*}$ & $75.5 \pm 4.0^{* * *}$ & $54.1 \pm 5.9^{* *}$ & $78.5 \pm 2.4^{* *}$ & $69.5 \pm 2.4^{* * *}$ & $59.3 \pm 3.1^{* * *}$ \\
\hline 12.5 & $69.1 \pm 3.7^{* * *}$ & $81.9 \pm 9.2^{*}$ & $53.1 \pm 6.3^{* *}$ & $72.4 \pm 7.3^{* *}$ & $59.1 \pm 7.3^{* * *}$ & $46.3 \pm 1.7^{* * *}$ \\
\hline 125 & $40.6 \pm 5.8^{* * *}$ & $45.4 \pm 4.9^{* * *}$ & $13.6 \pm 2.5^{* * *}$ & $43.2 \pm 8.6^{* *}$ & $41.6 \pm 8.6^{* *}$ & $18.1 \pm 3.6^{* * *}$ \\
\hline 6.25 & $60.6 \pm 4.1^{* *}$ & $50.3 \pm 1.9^{* * *}$ & $4.5 \pm 3.3^{* * *}$ & $75.3 \pm 3.2^{* * *}$ & $40.9 \pm 4.3^{* * *}$ & $11.3 \pm 2.9^{* * *}$ \\
\hline 12.5 & $67.8 \pm 2.2^{* * *}$ & $39.5 \pm 2.2^{* * *}$ & $17.5 \pm 7.1^{* * *}$ & $63.7 \pm 5.1^{* *}$ & $32.4 \pm 5.3^{* * *}$ & $8.2 \pm 2.3^{* * *}$ \\
\hline 125 & $25.7 \pm 3.5^{* * *}$ & $13.3 \pm 4.4^{* * *}$ & $0.1 \pm 3.2^{* * *}$ & $47.3 \pm 2.6^{* * *}$ & $21.3 \pm 4.2^{* * *}$ & $7.3 \pm 4.1^{* * *}$ \\
\hline
\end{tabular}

${ }^{1}$ For both cell lines and tests, the number of viable cells after treatment with PBS (no lactoferrin added) as control for each exposure time was set at $100 \%$. Results represent the percentage of viable cells for each condition. Means $( \pm$ SD) were calculated from 3 independent cultures and 8 measures for each culture.

${ }^{*} P<0.05 ;{ }^{* *} P<0.005$; and ${ }^{* * *} P<0.0005$ indicate significant changes compared with control (2-tailed unpaired Student's $t$-test).

the distance (in $\mu \mathrm{m}$ ) over time between the front cells in each edge of the wound. These distances correspond to an average of 3 independent cultures and 9 measures for each culture.

\section{Statistical Analysis}

Two-tailed, unpaired Student's $t$-test was used for the statistical evaluation of significant differences among the tested LF concentrations and exposure times compared with the control. Statistical analyses were performed in Microsoft Office Excel 2007 (Microsoft Corp., Redmond, WA).

\section{RESULTS}

\section{Cell Viability}

TB Method. The TB method distinguishes viable cells from dead cells, because dead cells are permeable to the dye and will be colored blue. The results obtained are compiled in Table 1. A decrease of more than $50 \%$ in the number of viable cells was obtained for increasing LF concentrations and exposure times and for both cell lines studied. Based on these experiments, 12.5 $\mu M$ LF was found to be effective in decreasing T47D cell viability compared with the control (set at $100 \%$ ) by between 28 and $54 \%$, depending on the exposure time. The differences obtained for the range of LF concentrations studied compared with the control were found to be statistically significant, except for 0.125 $\mu M$. Furthermore, the $P$-values obtained when comparing the different exposure times; namely, 24 and $48 \mathrm{~h}$, 48 and $72 \mathrm{~h}, 24$ and $72 \mathrm{~h}$, were 0.06, 0.08, and 0.05, respectively. For the HS578T cell line, the conditions that promoted a more pronounced decrease of cell viability were 72-h exposure to $125 \mu M$ LF. Nevertheless, at this exposure time and LF concentration, cellular lysis was observed (data not shown). Compared with the control, $12.5 \mu M$ LF decreased HS578T cell viability by between 18 and $47 \%$, depending on the exposure time. The differences obtained for all LF concentrations studied were statistically significant. Moreover, comparing the different exposure times, the differences obtained between 24 and $48 \mathrm{~h}$ were not statistically significant $(P$-value $=0.14)$, whereas the $P$-values obtained for the 48 and $72 \mathrm{~h}$ and 24 and $72 \mathrm{~h}$ comparisons were 0.02 and 0.03 , respectively.

MTS Method. The MTS assay is assumed to reflect cell number and is used to determine exposure-response relationships. Table 1 presents the results obtained in the MTS assays. Although slightly higher reductions in cell viability were found with this method, especially for the 72-h exposure, the tendencies were similar; thus, these results were found to be in agreement with those obtained with the TB dye method. Statistical significance was found for the comparisons between the different exposure times and the different LF concentrations used.

\section{Apoptosis}

The influence of LF in apoptosis was assessed by measuring caspase- 3 and caspase- 7 activities, because these are the effectors of the apoptosis machinery. Increasing concentrations of LF were found to increase such activities for both cell lines, as can be observed in Figure 1.

Generally, it was found that a decrease in apoptosis occurs with a 72-h exposure to LF. This result coincides 

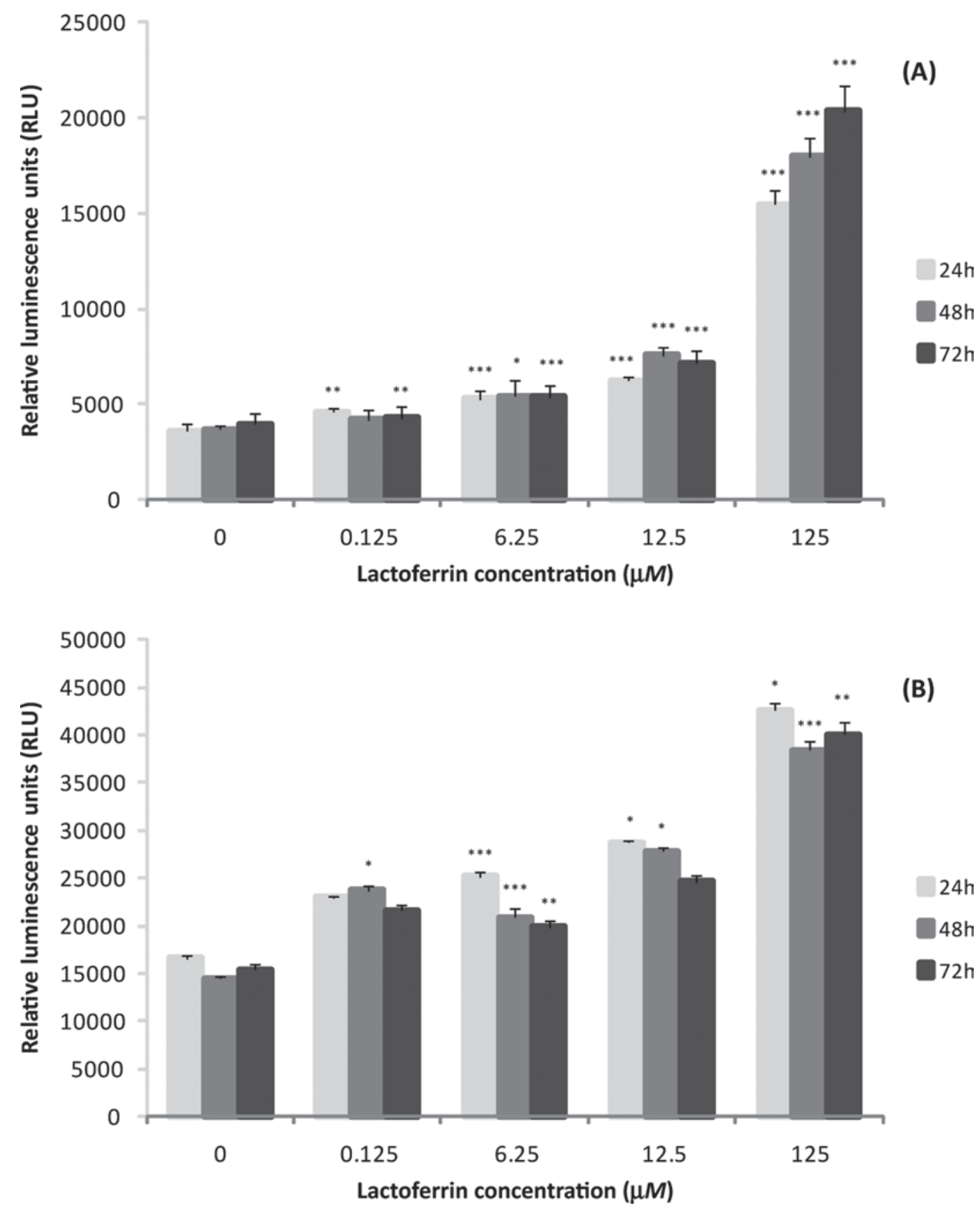

Figure 1. Effect of lactoferrin treatment $(0.125,6.25,12.5$, or $125 \mu M)$ on apoptosis in breast cancer cell lines HS578T (A) and T47D (B) for different exposure times $(24,48$, and $72 \mathrm{~h}$ ). Results represent an average of 3 independent cultures and 8 measures for each culture. Significant changes compared with control: ${ }^{*} P<0.05 ;{ }^{* *} P<0.005 ;{ }^{* * *} P<0.0005$ (2-tailed unpaired Student's $t$-test).

with the cellular lysis observed in the cell viability assays as described above. Although cell death was higher for a 72-h exposure to LF, necrosis was found to be the principal cellular death process occurring for this exposure time. For both cell lines, the caspase- 3 and caspase- 7 activities increased by 1.5 to 2 times for the lower LF concentrations studied (except for $0.125 \mu \mathrm{M}$
LF in the HS578T assays), the differences observed being statistically significant compared with the control. An increase of about 3 to 5 times in apoptosis levels was obtained in the experiments conducted with 125 $\mu M$ LF. It is important to note that the differences observed between the different exposure times were not, in most cases, statistically significant. 


\section{Cell Proliferation}

Based on the results from MTS, TB, and apoptosis assays, a 48-h exposure to $12.5 \mu M \mathrm{LF}$ was chosen for the cell proliferation experiments. The effect of LF on cell proliferation was studied using BrdU, a synthetic thymidine analog that binds to newly formed DNA in $\mathrm{S}$ phase, thus allowing the determination of the nuclei in proliferation. As expected from the previous results, LF was found to decrease the proliferation rates for both cell lines (Figure 2). Proliferation rate decreases of 35.5 and $52.5 \%$ were obtained for HS578T and T47D, respectively. The differences observed for the proliferation rates compared with the control experiments were found to be statistically significant for both cell lines $(P$ $<0.005$ for HS578T and $P<0.0005$ for T47D).

\section{Migration}

The LF concentration and exposure time used in the migration experiment was the same as those used to study cell proliferation. Lactoferrin was found to decrease the migration of both cell lines (Figure 3 and Figure 4) although the effect was more pronounced for T47D. From the statistical analysis, the differences observed for HS578T cells treated and untreated with LF were not significant $(P=0.116)$, but those observed for T47D were statistically significant $(P=0.001)$. The distance $(\mu \mathrm{m})$ between the front cells in each edge of the wound was higher for the cells exposed to $12.5 \mu \mathrm{M}$ LF for $48 \mathrm{~h}$ compared with the control (no LF added).

\section{DISCUSSION}

The role of milk proteins and peptides as physiologically active factors in the diet is being increasingly acknowledged (Marshall, 2004). Environmental factors, such as food and physical activity, have an important influence on the risk of cancer, thus delayed cancer development may be obtained by changing diet regimens. A large amount of data regarding the bioactivity of food components has been obtained using cell lines, and an important question regarding much of this work is the relevance of the concentrations used (Petricoin and Liotta, 2003).

In the current work, the influence of LF on cell viability for both cell lines was studied using 2 complementary tests, namely the TB dye method and bioreduction of the MTS reagent (Table 1). Some cytotoxicity assays allow the immediate interpretation of the results, such as the incorporation of a dye by dead cells or release of ${ }^{51} \mathrm{Cr}$ or fluorescein from prelabeled cells. These assays are viability assays and are intended for predicting survival and not directly assessing it, because they are good for identifying dead cells but can overestimate survival in the long term. Most of these assays involve cell membrane rupture and cell death. Cell viability is a measure of the metabolic status of a population and gives an indication of its growth potential. One of the simplest methods to evaluate cell viability is the dye exclusion approach, indicating the capacity of the cellular membrane to exclude a dye. The most commonly used dye is TB, and the method is based on the concept that viable cells do not absorb certain dyes whereas dead cells are permeable to them. Nevertheless, this method presents some disadvantages, such as also dyeing soluble proteins, causing stress to the cells, and being influenced by the presence of serum. Therefore, a complementary test for assessing cell viability was included in this study. The results obtained showed a decrease of more than $50 \%$ in the number of viable cells with increasing LF concentrations and exposure times for both cell lines studied. Although the results indicated that $72 \mathrm{~h}$ of exposure with $125 \mu M$ LF was the most effective treatment regarding a decrease in cell viability, cellular lysis was observed under these conditions. For that reason, and because cellular lysis is frequently associated with necrosis, such information was taken into consideration for the choice of the conditions to use $(12.5 \mu \mathrm{MLF}$ for $48 \mathrm{~h})$ in the subsequent experiments (the evaluations of proliferation and migration). Once necrosis occurs, the cellular contents are spilled into the surrounding tissues, causing inflammation and contamination of the neighbor cells with carcinogenic products. Therefore, the occurrence of necrosis is not a favorable occurrence when the goal is treating cancer (Werner et al., 2005).

The results obtained in these experiments are in accordance with data previously reported for LF effects on other human cancer cell lines (Hakansson et al., 1995; Tsuda et al., 2004; Xiao et al., 2004). As described above, many other viability assays exist, such as the bioreduction of the MTS reagent, that measure the metabolic events occurring in the cell, allowing a more precise quantification because they are more sensitive. These reductions take place only when reductase enzymes are active, and therefore conversion is often used as a measure of viable cells. However, such colorimetric assays also present disadvantages regarding interference from the culture medium, reversible metabolic inhibitions, and different colorimetric responses for different types of cells. It is also important to keep in mind that other viability tests sometimes give completely different results, as many different conditions can increase or decrease metabolic activity. Changes in metabolic activity can give large changes in MTS results even though the number of viable cells is constant. When the amount of (purple) formazan produced by cells 
treated with an agent, such as LF, is compared with the amount of formazan produced by untreated control cells, the effectiveness of the agent causing death or changing the metabolism of the cells can be deduced through a dose-response curve. Results gathered from these experiments were similar to those obtained with the TB method. Furthermore, although the higher LF concentration studied $(125 \mu \mathrm{M})$ was the most effective, this concentration would represent an unreasonable daily intake of milk or dairy products, considering that
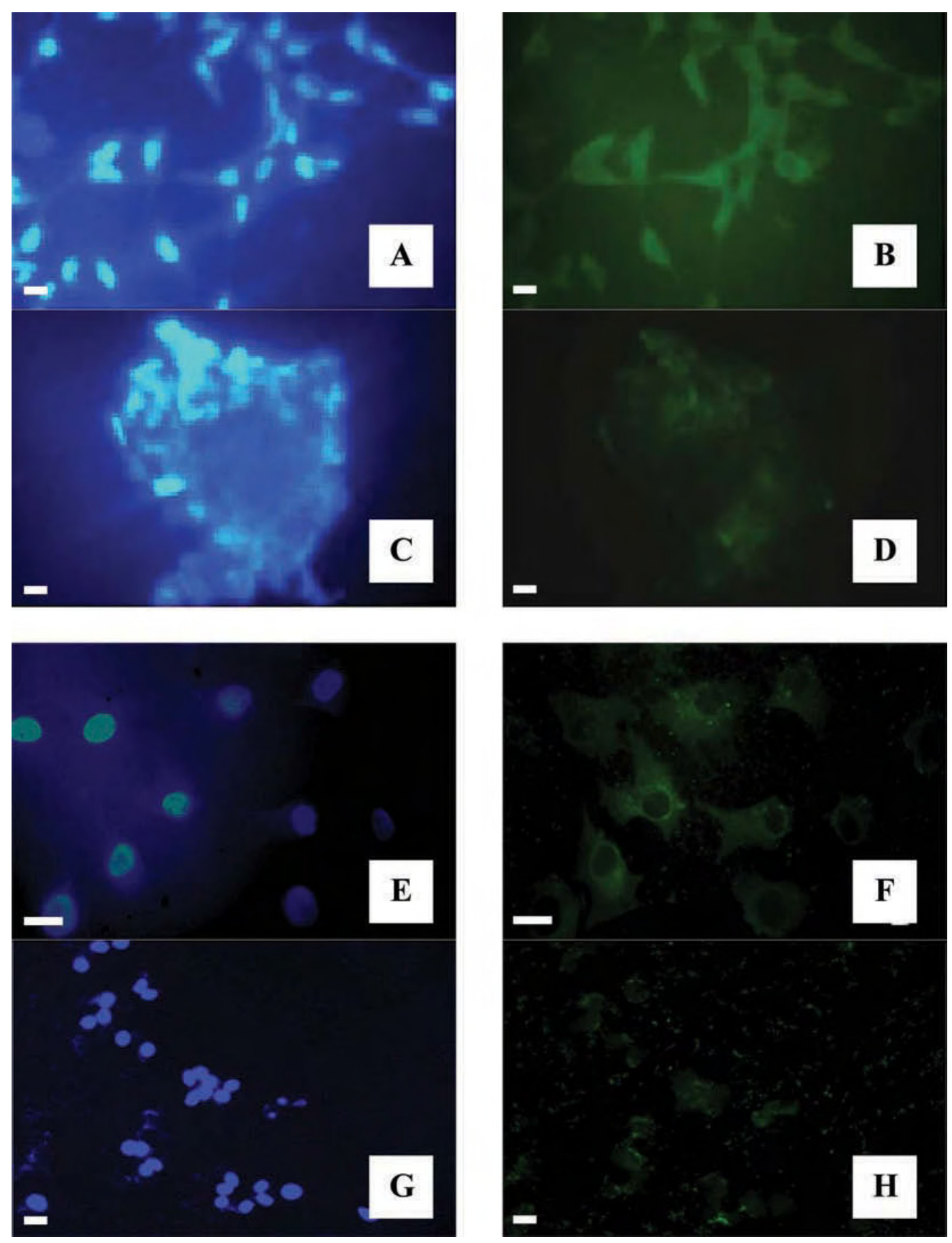

Figure 2. Effect of lactoferrin (LF) treatment (12.5 $\mu M$; 48-h exposure) on cell proliferation. Control samples (with no LF added) were included for both cell lines. Panels $\mathrm{A}$ and $\mathrm{C}=$ total nuclei in control and treated T47D cells, respectively; panels $\mathrm{B}$ and $\mathrm{D}=$ nuclei in proliferation in control and treated T47D cells, respectively. Panels E and $\mathrm{G}=$ total nuclei in control and treated HS578T cells, respectively; panels $\mathrm{F}$ and $\mathrm{H}$ $=$ nuclei in proliferation in control and treated HS578T cells, respectively; 40× magnification used; scale bar $=10 \mu \mathrm{m}$. 

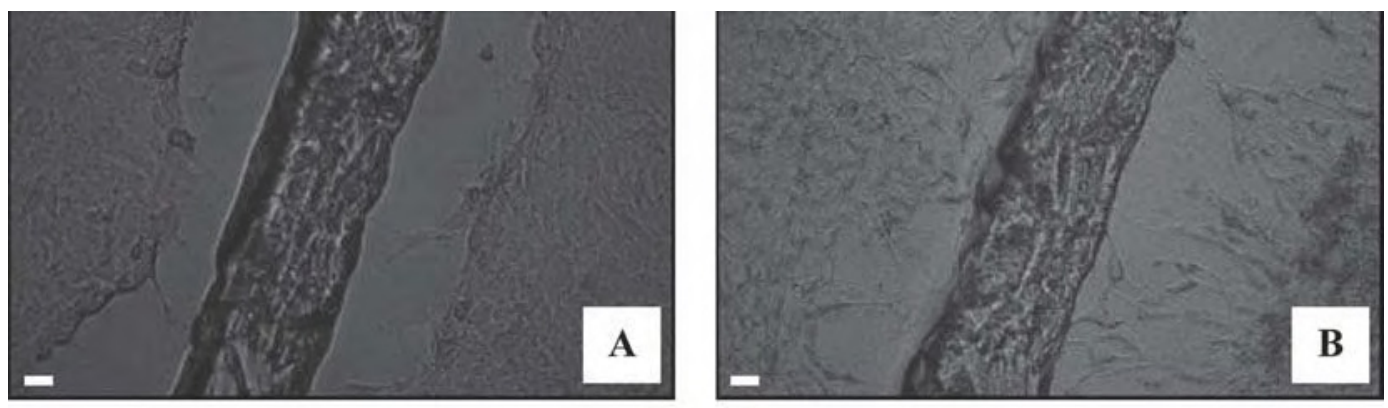

\begin{tabular}{c|c|c}
\hline & \multicolumn{2}{|c}{ [Distance $\boldsymbol{\mu} \mathbf{m}]$} \\
Time (h) & $\mathbf{0} \boldsymbol{\mu} \mathbf{M} \mathbf{~ L F}$ & $\mathbf{1 2 . 5} \boldsymbol{\mu} \mathbf{M} \mathbf{L F}$ \\
\hline 0 & $179 \pm 2$ & $167 \pm 3$ \\
3 & $172 \pm 1$ & $162 \pm 3$ \\
6 & $100 \pm 3$ & $116 \pm 4$ \\
9 & $98 \pm 2$ & $109 \pm 1$ \\
24 & $72 \pm 3$ & $82 \pm 6$ \\
27 & $50 \pm 12$ & $48 \pm 2$ \\
30 & $20 \pm 10$ & $27 \pm 2$ \\
34 & $13 \pm 6$ & $26 \pm 4$ \\
48 & $0 \pm 1$ & $6 \pm 3$ \\
\hline
\end{tabular}

Figure 3. Effect of lactoferrin (LF) treatment (12.5 $\mu M$; 48-h exposure) on migration of HS578T cells: A) 0-h exposure to LF; B) 48-h exposure to LF. The table summarizes the distances $(\mu \mathrm{m})$ over time between the front cells in each edge of the wound, and the results represent an average of 3 independent cultures and 9 measures for each culture. Control samples (with no LF added) were included; 40× magnification used; scale bar $=10 \mu \mathrm{m}$.
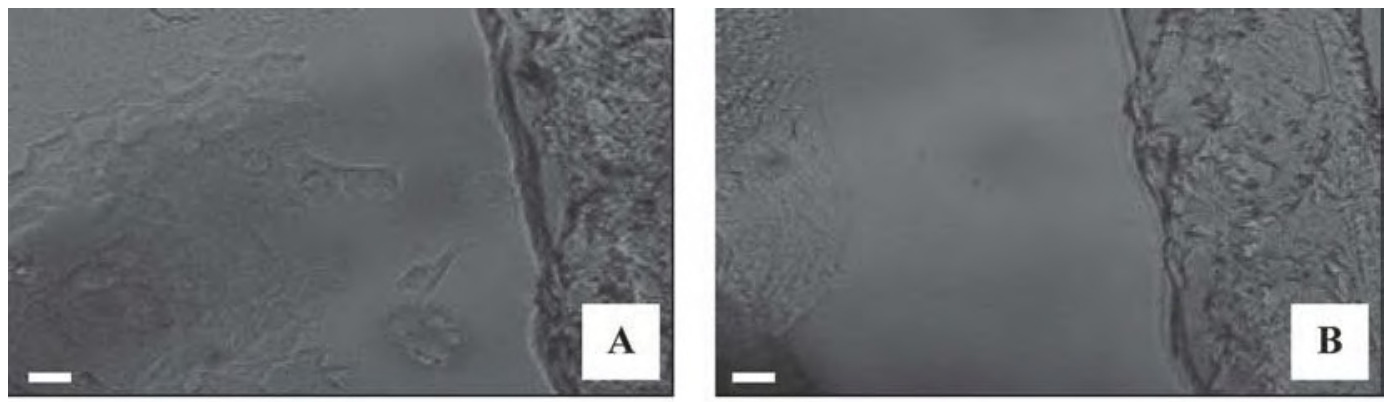

\begin{tabular}{c|c|c}
\hline & \multicolumn{3}{|c}{$[$ Distance $\boldsymbol{\mu} \mathbf{m}]$} \\
Time (h) & $\mathbf{0} \boldsymbol{\mu} \mathbf{M} \mathbf{~} \mathbf{F}$ & $\mathbf{1 2 . 5} \boldsymbol{\mu} \mathbf{M} \mathbf{~ L F}$ \\
\hline 0 & $382 \pm 8$ & $380 \pm 3$ \\
3 & $372 \pm 19$ & $379 \pm 2$ \\
6 & $257 \pm 14$ & $366 \pm 3$ \\
9 & $222 \pm 12$ & $373 \pm 9$ \\
24 & $166 \pm 12$ & $380 \pm 10$ \\
27 & $116 \pm 13$ & $390 \pm 6$ \\
30 & $103 \pm 9$ & $377 \pm 6$ \\
34 & $87 \pm 5$ & $377 \pm 4$ \\
48 & $87 \pm 5$ & $386 \pm 4$ \\
\hline
\end{tabular}

Figure 4. Effect of lactoferrin (LF) treatment (12.5 $\mu M$; 48-h exposure) on migration of T47D cells: A) 0-h exposure to LF; B) 48-h exposure to LF. The table summarizes the distances $(\mu \mathrm{m})$ over time between the front cells in each edge of the wound, and the results represent an average of 3 independent cultures and 9 measures for each culture. Control samples (with no LF added) were included; 40× magnification used; scale bar $=10 \mu \mathrm{m}$. 
a major part of ingested LF survives passage through the gut (Troost et al., 2001). Therefore, $12.5 \mu M \mathrm{LF}$ was chosen for the subsequent experiments.

Cell viability usually results from the balance between cell growth/proliferation and cell death. In addition, cell death can occur by 1 of 2 mechanisms: necrosis or apoptosis (Werner et al., 2005). Cells undergoing apoptosis are characterized by cell shrinkage, chromatin condensation, DNA fragmentation, and membrane dissembling (Hakansson et al., 1995; Mader et al., 2005). Two main pathways have been reported to mediate apoptosis (Mader et al., 2005). One is the death receptor pathway, which is triggered by ligand-inducing aggregation of death receptors, such as the Fas protein (Fujita et al., 2004). The second pathway is related to the activation of the mitochondrial response to cytotoxic drug-induced cellular stress (Mader et al., 2005). Our results clearly showed an effect of LF in the apoptotic levels based on the activities of caspase- 3 and caspase- 7 (effectors of the apoptosis machinery) and confirmed the cellular lysis occurring with $72 \mathrm{~h}$ of exposure to the higher protein concentration used. According to Sakai and coworkers (2005), pepsin-digested bovine LF influences the apoptosis machinery by activating the JKSAPK signaling pathway in the human oral squamous cell carcinoma cell line, SAS. Those authors found that treatment with pepsin-digested bovine LF induced cell death with apoptotic nuclear changes preceded by the cleavage of caspase-3 and poly(ADP-ribose) polymerase (PARP) in the apoptotic cells. Moreover, the peptide induced phosphorylation of extracellular signal-regulated kinase (ERK1/2), a member of the MAP kinase family, in the early stages of apoptosis. Another MAP kinase, c-Jun N-terminal kinase/stress-activated protein kinase (JNK/SAPK), was also phosphorylated by treatment with pepsin-digested LF. Other authors (Hakansson et al., 1995; Roy et al., 2002) have reported that LF and related compounds induce the genetic expression of Fas (Fujita et al., 2004), which is involved in triggering apoptosis. Roy et al. (2002) determined the effects of LF and several protein hydrolysates on the growth of human myeloid leukemic cells (HL-60). They showed that bovine milk contains biochemical factors with potent cytotoxic properties against some tumor cells and that the key factors are mostly inactive within the structure of the precursor compounds but can be released by enzymatic proteolysis. Moreover, a report from Tomita et al. (1994) provided evidence of in vivo production of lactoferricin $\mathrm{B}$ by isolating the peptide from the gastrointestinal contents of rats fed a diet containing bovine LF. Based on these evidences, it is likely that the activity of LF in apoptosis and cell growth is due mostly to its major peptide (lactoferricin); therefore, further studies are required to clarify the possible mechanisms involved and to determine if LF could be degraded and to what extent in the culture medium.

As mentioned previously, cell proliferation is an important factor affecting cell viability. As expected from the cell viability tests and the apoptosis study, proliferation rates were found to decrease for both cell lines when exposed to LF, this effect being more pronounced for T47D. According to Xiao and coworkers (2004), LF has an effect in the cell cycle machinery by influencing the genetic expression of some of its key components. Lactoferrin is known to detain cancer cells in the $G_{1}$ phase or to force them to enter the $G_{0}$ (latency) phase (Ward et al., 2005). The cell cycle machinery is mainly regulated by cyclin-dependent kinases (cdk) that are responsible for the progression through the cell cycle phases (Damiens et al., 1999). In addition, the retinoblastoma protein $(\mathrm{pRb})$ is known to inhibit cycle progression, although it is frequently phosphorylated by cdk, causing loss of functionality (Damiens et al., 1999). The mechanism by which LF inhibits cell proliferation may be related to the fact that it inhibits cdk and cyclin E genetic expression (Xiao et al., 2004). Furthermore, LF has been reported to increase the expression of $\mathrm{pRb}, \mathrm{p} 21$, and $\mathrm{p} 27$, inhibitors of the cell cycle (Damiens et al., 1999; Rodrigues et al., 2009). It is important to note that LF possesses an ERE in its gene. The ERE is probably a key component for the antiproliferation effect of LF, because it confers on LF the ability to interfere in genetic expression (Stokes et al., 2004). According to Baumrucker (2000), LF also affects cell growth by interacting with epidermal growth factor binding protein 3 , which usually binds to the epidermal growth factor, exerting a protective effect and thus helping cellular growth. Competing with epidermal growth factor for epidermal growth factor binding protein 3, LF prevents the stimulation of cell growth. In spite of the information gathered in this preliminary study, further research should be conducted to determine the expression of cell cycle regulatory proteins as a starting point to disclose the mechanisms by which LF exerts its effect in cell proliferation. When a cancer has developed, it would be beneficial if food components could slow the rate of tumor growth; therefore, the effect of LF on cell growth rates should be assessed in a longterm treatment, because the daily intake of milk and dairy products might not be sufficient to produce an immediate physiologically relevant dose (Freiburghaus et al., 2009).

Cell migration is a key mechanism in the development of metastasis and tissue invasion. Therefore, any agent that can impair cell migration will yield a positive response in cancer treatment and recurrence. Figures 3 and 4 show that LF decreased the migration in both 
cell lines, even for HS578T cells (Figure 3) that have a higher migration potential (mainly because of the lack of estrogen receptor expression) compared with T47D (Figure 4), for which the effect was more pronounced. This may be related to the fact that LF interacts with cadherins and integrins (von Schlippe et al., 2000), which in part can explain the cell detachment that occurred for T47D cells. Although these results would be more relevant if a greater effect had been observed for HS578T cells (as these are ER - and correspond to a more aggressive type of tumor for which existing therapy is not very efficient), this study is one of the first assessments on the effect of LF on migration (Ariazi et al., 2002; Giacotti, 2006; Neve et al., 2006). Moreover, the results obtained for T47D suggest that a combination of estrogen and LF could be further explored for breast cancer treatment.

Although further research on the effects of LF on breast cancer is required, the findings of this study are very promising and of particular relevance for the food industry in general. The intake of milk and dairy products, or even food products enriched with LF, may be a natural way of preventing breast cancer or enhancing treatment.

\section{CONCLUSIONS}

From the results gathered in this work, it was found that a 48-h exposure to $12.5 \mu M$ LF decreases cell viability and proliferation for both cell lines studied. Furthermore, these conditions promoted an increase in apoptosis. Although the mechanisms of LF action are not fully understood, evidence points to the ability of $\mathrm{LF}$ to interact with some receptors and to modulate genetic expression of several molecules that are vital to the cell cycle and apoptosis machinery. Moreover, LF was shown to decrease the ability of both cell lines to migrate. Lactoferrin has great potential to be used in breast cancer treatment.

\section{ACKNOWLEDGMENTS}

The authors acknowledge the Institute of Molecular Pathology and Immunology of the University of Porto (IPATIMUP, Porto, Portugal) for kindly providing the breast cancer cell lines used in this work.

\section{REFERENCES}

Ariazi, E. A., G. M. Clark, and J. E. Mertz. 2002. Estrogen-related receptor alpha and estrogen-related receptor gamma associate with unfavorable and favorable biomarkers, respectively, in human breast cancer. Cancer Res. 62:6510-6518.
Babina, E., D. Semenov, V. Buneva, and G. Nevisnkii. 2005. Human milk lactoferrin hydrolyses nucleoside-5'-triphosphates. Mol. Biol. 39:513-520.

Baumrucker, C. 2000. Mammary mechanisms for lactoferrin: Interactions with IGFBP3. Biotechnol. Agron. Soc. Environ. 4:5-12.

Bezault, J., R. Bhimani, J. Wiprovnick, and P. Furmanski. 1994. Human lactoferrin inhibits growth of solid tumors and development of experimental metastases in mice. Cancer Res. 54:2310-2312.

Damiens, E., I. Yazidi, J. Mazurier, I. Duthile, G. Spik, and Y. Boilly-Marer. 1999. Lactoferrin inhibits G1 cyclin-dependent kinases during growth arrest of human breast carcinoma cells. J. Cell. Biochem. 74:486-498.

Ferguson, L. R. 2009. Nutrigenomics approaches to functional foods. J. Am. Diet. Assoc. 109:452-458.

Freiburghaus, C., B. Janicke, H. Lindmark-Månsson, S. M. Oredsson, and M. A. Paulsson. 2009. Lactoferricin treatment decreases the rate of cell proliferation of a human colon cancer cell line. J. Dairy Sci. 92:2477-2484

Fujita, K.-I., E. Matsuda, K. Sekine, M. Iigo, and H. Tsuda. 2004. Lactoferrin enhances Fas expression and apoptosis in the colon mucosa of azoxymethane-treated rats. Carcinogenesis 25:1961-1966.

Giacotti, V. 2006. Breast cancer markers. Cancer Lett. 243:145-159.

Gill, H. S., F. Doull, K. J. Rutherfurd, and M. L. Cross. 2000. Immunoregulatory peptides in bovine milk. Br. J. Nutr. 84(Suppl. 1):S111-S117.

Hakansson, A., B. Zhivotovski, S. Orrenius, H. Sabharwal, and C. Svanbory. 1995. Apoptosis induced by a human milk protein. Proc. Natl. Acad. Sci. USA 92:8064-8068.

Hanahan, D., and R. Weinberg. 2000. The hallmarks of cancer. Cell 100:57-70.

Iigo, M., D. Alexander, N. Long, J. Xu, K. Fukamachi, M. Futakuchi, M. Takase, and H. Tsuda. 2009. Anticarcinogenesis pathways activated by bovine lactoferrin in the murine small intestine. Biochimie 91:86-101.

Jacobs, D. R., M. Gross, and L. Tapsell. 2009. Food synergy: An operational concept for understanding nutrition. Am. J. Clin. Nutr. 89:1543S-1548S.

Jemal, A., R. Siegel, E. Ward, Y. Hao, J. Xu, and M. J. Thun. 2009. Cancer Statistics, 2009. CA Cancer J. Clin. 59:225-249.

Korhonen, H., and A. Pihlanto. 2006. Bioactive peptides: Production and functionality. Int. Dairy J. 16:945-960.

Legrand, D., E. Elass, M. Carpentier, and J. Mazurier. 2005. Lactoferrin: A modulator of immune and inflammatory responses. Cell. Mol. Life Sci. 62:2549-2559.

Mader, J. S., J. Salsman, D. Conrad, and D. Hoskin. 2005. Bovine lactoferricin selectively induces apoptosis in human leukaemia and carcinoma cell lines. Mol. Cancer Ther. 4:612-624.

Marshall, K. 2004. Therapeutic applications of whey protein. Altern. Med. Rev. 9:136-156.

McCabe-Sellers, B., C. Chenard, D. Lovera, C. Champagne, M. Bogle, and J. Kaput. 2009. Readiness of food composition databases and food component analysis systems for nutrigenomics. J. Food Compost. Anal. 22:S57-S62.

Neve, R. M., K. Chin, J. Fridlyand, J. Yeh, F. L. Baehner, T. Fevr, L. Clark, N. Bayani, J.-P. Coppe, F. Tong, T. Speed, P. T. Spellman, S. DeVries, A. Lapuk, N. J. Wang, W.-L. Kuo, J. L. Stilwell, D. Pinkel, D. G. Albertson, F. M. Waldman, F. McCormick, R. B. Dickson, M. D. Johnson, M. Lippman, S. Ethier, A. Gazdar, and J. W. Gray. 2006. A collection of breast cancer cell lines for the study of functionally distinct cancer subtypes. Cancer Cell 10:515-527.

Pan, Y., M. Rowney, P. Guo, and P. Hobman. 2007. Biological properties of lactoferrin: An overview. Aust. J. Dairy Technol. 62:3142.

Perdigon, G., A. De Moreno de LeBlanc, J. Valdez, and M. Rachid. 2002. Role of yoghurt in the prevention of colon cancer. Eur. J. Clin. Nutr. 56:S65-S68.

Petricoin, E. F., and L. Liotta. 2003. Clinical applications of proteomics. J. Nutr. 133:2476S-2484S. 
Rodrigues, L. R., J. Teixeira, F. Schmitt, M. Paulsson, and H. Lindmark-Mansson. 2009. Lactoferrin and cancer prevention. Crit. Rev. Food Sci. Nutr. 49:203-217.

Roy, M. K., Y. Kuwabara, K. Hara, Y. Watanabe, and Y. Tamai. 2002. Peptides from the N-terminal end of bovine lactoferrin induces apoptosis in human leukemic (HL60) cells. J. Dairy Sci. 85:2065-2074.

Sakai, T., Y. Banno, Y. Kato, Y. Nazawa, and M. Kawaguchi. 2005. Pepsin-digested bovine lactoferrin induces apoptotic cell death with JNK/SAPK activation in oral cancer. J. Pharmacol. Sci. 98:41-48.

Schiff, R., and C. Osborne. 2005. New insight into estrogen receptor $\alpha$ function and its implication for endocrine therapy resistance in breast cancer. Breast Cancer Res. 7:205-211.

Stokes, K., B. Alston-Mills, and C. Teng. 2004. Estrogen response element and the promoter context of the human and mouse lactoferrin genes influence estrogen receptor alpha-mediated transactivation activity in mammary gland cells. J. Mol. Endocrinol. 33:315-334.

Teng, C. T. 2006. Factors regulating lactoferrin gene expression. Biochem. Cell Biol. 84:263-267.

Tomita, M., M. Takase, W. Bellamy, and S. Shimura. 1994. A review: The active peptide of lactoferrin. Acta Paediatr. Jpn. 36:585591.

Tomita, M., H. Wakabayashi, K. Yamauchi, S. Teraguchi, and H. Hayasawa. 2002. Bovine lactoferrin and lactoferricin derived from milk: Production and applications. Biochem. Cell Biol. 80:109-112.

Troost, F. J., J. Steijns, W. H. M. Saris, and R.-J. M. Brummer. 2001. Gastric digestion of bovine lactoferrin in vivo in adults. J. Nutr. 131:2101-2104.

Tsuda, H., T. Kozu, G. Inuma, Y. Ohashi, Y. Saito, D. Saito, T. Akasu, D. B. Alexander, M. Futakuchi, K. Fukamachi, J. Xu, T. Kakizoe, and M. Iigo. 2010. Cancer prevention by bovine lactoferrin: From animal studies to human trial. Biometals 23:399-409.
Tsuda, H., Y. Ohshima, H. Nomoto, K. Fujita, E. Matsuda, M. Iigo, N. Takasuka, and M. A. Moore. 2004. Cancer prevention by natural compounds. Drug Metab. Pharmacokinet. 19:245-263.

Tsuda, H., K. Sekine, K. Fujitaand, and M. Iigo. 2002. Cancer prevention by bovine lactoferrin and underlying mechanisms - A review of experimental and clinical studies. Biochem. Cell Biol. 80:131-136.

Tsuda, H., K. Sekine, Y. Ushida, T. Kuhara, N. Takasuka, M. Iigo, B. S. Hans, and M. A. Moore. 2000. Milk and dairy products in cancer prevention: Focus on bovine lactoferrin. Mutat. Res. 462:227-233.

von Schlippe, M., J. F. Marshall, P. Perry, M. Stone, A. J. Zhu, and I. R. Hart. 2000. Functional interaction between E-cadherin and alphav-containing integrins in carcinoma cells. J. Cell Sci. 113:425-437.

Wakabayashi, H., K. Yamauchi, and M. Takase. 2006. Lactoferrin research, technology and applications. Int. Dairy J. 16:1241-1251.

Ward, P. P., E. Paz, and O. Conneely. 2005. Multifunctional roles of lactoferrin: A critical overview. Cell. Mol. Life Sci. 62:25402548.

Werner, H. M., J. Franke, and R. Vermes. 2005. Apoptosis and proliferation in breast cancer cells cultured in vitro: Effects on SERMs. Climacteric 8:294-299.

Xiao, Y., C. Monitto, K. Minhas, and D. Sidranski. 2004. Lactoferrin down-regulates G1 cyclin-dependent kinases during growth arrest of head and neck cancer cells. Clin. Cancer Res. 10:8683-8686.

Xu, X. X., H. R. Jiang, H. B. Li, T. N. Zhang, Q. Zhou, and Q. Liu 2010. Apoptosis of stomach cancer cell SGC-7901 and regulation of Akt signaling way induced by bovine lactoferrin. J. Dairy Sci. 93:2344-2350.

Zemann, N., P. Klein, E. Wetzel, F. Huettinger, and M. Huettinger. 2010. Lactoferrin induces growth arrest and nuclear accumulation of Smad-2 in HeLa cells. Biochimie 92:880-884. 